\title{
Partidos de creación interna bajo las dictaduras: liberales avanzados y moderados durante el periodo del Estatuto Real en España (1834-1836)
}

\author{
Parties of internal creation under dictatorships: Advanced and moderate \\ liberals during the period of the Royal Statute in Spain (1834-1836)
}

\author{
PEDRO LAGO \\ Universidad de Santiago de Compostela
}

\section{Cómo citar/Citation}

Lago, P. (2020). Partidos de creación interna bajo las dictaduras: liberales avanzados y moderados durante el periodo del Estatuto Real en España (1834-1836). Revista Española de Ciencia Política, 53, 95-117.

Doi: https://doi.org/10.21308/recp.53.04

\section{Resumen}

De acuerdo con la actual investigación sobre los partidos en las dictaduras, su origen es el resultado de la acción de autócratas e individuos excluidos de la representación parlamentaria. La hipótesis de que los partidos puedan surgir en las cámaras electas a través de coaliciones legislativas no se ha contemplado. Sin embargo, en esas cámaras también pueden concurrir los incentivos e información predichos por el modelo de coalición duradera. Eso implica que los parlamentos pueden convertirse en un espacio multidimensional con conflictos distributivos donde se produce un voto sofisticado. Para comprobar esta hipótesis, este trabajo analiza las coaliciones de liberales avanzados y moderados en el Estamento de Procuradores durante el régimen del Estatuto Real (1834-1836). Los resultados muestran con claridad que, efectivamente, los procuradores convirtieron esta Cámara electa en un espacio multidimensional, donde se produjeron conflictos distributivos y ejercieron el voto estratégico. Las votaciones nominales registradas en el Diario de Sesiones de Cortes del Estatuto Real. Estamento de Procuradores (legislaturas de 1834-35, 1835-36 y 1836) constituyen la principal fuente de información.

Palabras clave: coalición duradera, conflicto distributivo, espacio multidimensional, voto estratégico.

\footnotetext{
Abstract

According to the current research on parties in dictatorships, the origin of parties is the result of the action by autocrats and individuals excluded from parliamentary representation. The
} 
hypothesis that parties are created in elected chambers through legislative coalitions has not been examined. However, the incentives and information predicted by the long-lasting coalition model can also occur in these chambers. That implies that parliaments can become a multidimensional space with distributive conflicts where sophisticated voting takes place. In order to test this hypothesis, this article analyzes the coalitions of advanced and moderate liberals within the Estamento de Procuradores during the regime of the Royal Statute (18341836). The results clearly show that the procuradores turned that elected chamber into a multidimensional space where distributive conflicts arose, and strategic voting was used. Nominal votes recorded in the Diario de Sesiones de Cortes del Estatuto Real. Estamento de Procuradores (1834-35, 1835-36 and 1836 terms) are the main source of information.

Keywords: long-lasting coalition, distributive conflict, multidimensional space, strategic voting.

\section{INTRODUCCIÓN}

La reciente literatura sobre cámaras electas y partidos en el autoritarismo está dominada por dos perspectivas analíticas. Por un lado, la creación de parlamentos y partidos en las dictaduras — regímenes despóticos, autoritarios y totalitarios (Colomer, 2009: 155-161) - se explica como una estrategia de supervivencia política de los autócratas ${ }^{1}$. Se trata de iniciativas para enfrentarse a dos problemas: la neutralización de rebeliones y la obtención de cooperación (Gandhi, 2008; Gandhi y Przeworski, 2007; Geddes et al., 2018). Por otro, el origen de los partidos gobernantes y los partidos que acceden al poder se explica por la acción de autócratas — normalmente antes de la formación de la asamblea legislativa-y por la de individuos excluidos de la representación parlamentaria, respectivamente (Geddes, 1999, 2005, 2008; Geddes et al., 2018).

Sin embargo, los estudios históricos muestran la presencia de candidatos no adscritos a un partido y alianzas legislativas en Cámaras electas de regímenes despóticos de la Restauración europea. Las facultades legislativas de estas Cámaras se ven reducidas en comparación con las Asambleas Revolucionarias anteriores por la introducción de tres cambios institucionales: a) el Parlamento pasa a ser bicameral, donde la Cámara Alta se configura como un órgano de naturaleza aristocrática, cuyos miembros son natos o designados por el rey entre los estratos altos de la sociedad y del Estado; b) el rey, además de disponer de la facultad de sancionar, es el único titular de la potestad legislativa: de modo que la Cámara no puede deliberar en ningún caso si no lo hace a impulso del monarca, y c) el monarca se reserva la facultad de convocar,

1. Un país se define como democrático si cumple las siguientes condiciones. Primero, el Ejecutivo es elegido directa o indirectamente en elecciones populares y es responsable directamente ante los votantes o ante el Parlamento. Segundo, el Parlamento (o el Ejecutivo si se elige directamente) se elige en elecciones libres y justas. Tercero, la mayoría de los hombres adultos tienen derecho a votar (Boix et al., 2013). 
suspender y disolver el Parlamento (Aprile et al.,, 2013; Blanco, 2010; Caron y Luis, 2015; Huntington, 1994; Prutsch, 2013; Rosanvallon, 1994).

No constituye un asunto histórico menor, ya que estas Cámaras electas se extienden a seis países, a saber: Francia con la Carta Otorgada de 1814; Polonia con la Constitución de 1815; Portugal con la Carta Otorgada de 1826; varios estados alemanes con cartas constitucionales entre 1816 y 1831; Espańa con el Estatuto Real de 1834, e Italia con el Estatuto Albertino (1847), la Constitución de las Dos Sicilias (1848) y el Estatuto del Gran Ducado de Toscana (1848)².

Un caso paradigmático de coaliciones legislativas que derivan en la articulación de partidos gobernantes acontece en el Estamento de Procuradores de las Cortes durante el régimen del Estatuto Real (1834-1836). Desde el inicio de la primera legislatura se configuraron las coaliciones avanzada y moderada. A partir de ellas, se estructuraron los dos primeros partidos de España: el Partido Progresista (PP) y el Partido Moderado (PM), (Burdiel, 1987).

La formación de estos partidos en las democracias ha sido explicada desde el esquema teórico de la coalición duradera (Aldrich, 1995; 2011), según el cual, un conjunto de parlamentarios alcanza un acuerdo ex ante para seguir un curso de acción común sobre una serie de cuestiones. Esta explicación fue testada por Aldrich (ibid.) en su estudio de las primeras legislaturas del Congreso de los Estados Unidos, que muestra la articulación de las coaliciones legislativas federalista y jeffersoniano-republicana.

En este trabajo, argumento que dicho modelo resulta generalizable a las dictaduras por dos razones. Por una parte, en las Cámaras electas de regímenes autocráticos también pueden concurrir los incentivos e información propiciatorios de una coalición duradera. Por otra, aunque las reglas institucionales disminuyen los posibles beneficios legislativos de una coalición duradera, hay una potencial ganancia para este tipo de alianza entre los representantes disidentes. El Parlamento se puede convertir en un foro para demandar públicamente el cambio de régimen, que puede conectarse con diferentes acciones fuera de la Cámara electa. Y los parlamentarios defensores del régimen, en caso de no estar organizados en un partido, pueden hacer lo mismo para enfrentarse a sus oponentes. Evidentemente, también pueden darse coaliciones legislativas con objetivos intermedios. Los parlamentarios se pueden coordinar para promover reformas parciales.

La investigación cuantitativa de las coaliciones legislativas en las Cámaras electas de la Restauración europea se encuentra con un problema de acceso a información estadística. No se dispone de datos sistemáticos sobre cuestiones debatidas, conflictos distributivos o votaciones nominales registradas. De este modo, no es posible el análisis comparado cuantitativo que posibilite la inferencia estadística. Pero cabe la posibilidad de recurrir al estudio de un caso que ponga en cuestión el saber establecido (Gerring, 2007; Rohlfing, 2012). En este sentido, la información acumulada por los

2. Disponible en: http://modernconstitutions.de/;hhtp://www.dircost.unito.it/index.shtml. 
historiadores sobre las tres legislaturas del Estamento de Procuradores de las Cortes españolas permite reconstruir con minuciosidad la respuesta de los procuradores a las reglas y prácticas institucionales. Con ello, se puede comprobar la validez del esquema teórico de la coalición duradera para explicar la articulación de partidos en las dictaduras.

El resto del artículo se divide en cuatro secciones. En la segunda se exponen los microfundamentos de la coalición duradera y su aplicabilidad a los contextos de decisión de las dictaduras. La tercera sección incluye la metodología y los datos utilizados en la investigación. En el apartado siguiente se presenta el análisis empírico de las coaliciones legislativas en el Estamento de Procuradores. El quinto apartado recoge las principales conclusiones y se esbozan posibles líneas de investigación futuras.

\section{ARGUMENTOS TEÓRICOS}

La explicación de la formación de partidos en las democracias se basa en dos tipos de partido: de origen interno y origen externo. En el primero, los partidos surgen en las Asambleas Legislativas, por medio de coaliciones de parlamentarios. En el segundo, el proceso se inicia fuera del marco parlamentario, a través de promotores como sindicatos, periódicos o círculos intelectuales (Duverger, 1987). En cambio, la explicación de la formación de partidos en las dictaduras contempla únicamente el tipo de partido de origen externo; ya sea por iniciativa de autócratas o individuos excluidos de la Cámara electa (Geddes, 1999, 2005, 2008; Geddes et al., 2018).

Frente a esta explicación excluyente del partido de origen interno, en este trabajo defiendo la hipótesis alternativa: los incentivos e información propiciatorios de la articulación de este tipo de partido también se pueden dar en las dictaduras. Estos incentivos e información vienen dados por la interacción entre las propiedades de las votaciones de comité, los ciclos de votaciones, el espacio temático multidimensional, los conflictos distributivos y el voto sofisticado (Aldrich, 1995, 2011). Los parlamentarios pueden apostar o no por formar una coalición legislativa, pero en caso de hacerlo estas condiciones tienen que estar presentes.

Las votaciones de las Cámaras electas de las dictaduras poseen las propiedades de las votaciones de comité. Primero, el recurso de los representantes para influir en las decisiones colectivas es el voto. Segundo, en las votaciones de las Cámaras electas se utiliza habitualmente la regla de la mayoría. Tercero, los parlamentarios votan directamente por alternativas y no por candidatos, como en las elecciones masivas. Cuarto, las alternativas atienden a la provisión de bienes públicos (Hinich y Munger, 1997; Shepsle y Bonchek, 1997).

La agregación directa de los votos de los representantes por medio de la regla de la mayoría no garantiza necesariamente un ganador de Condorcet en las Cámaras electas de las autocracias: una alternativa que vence a cualquier otra alternativa en una elección binaria bajo la regla de la mayoría. Se trata de un problema de inestabilidad generado por la circularidad de las votaciones, que no permite identificar la alternativa más 
preferida por la Cámara electa. Como el teorema de imposibilidad de Arrow demuestra, ningún método de elección puede garantizar que se obtendrán preferencias sociales no cíclicas a partir de preferencias individuales no cíclicas (Arrow, 1963; Hinich y Munger, 1997; Shepsle y Bonchek, 1997).

Esta inestabilidad se acrecienta cuando la Cámara electa constituye un espacio temático multidimensional. Esto es, se vota a favor o en contra de diferentes cuestiones decididas en votaciones separadas. Una situación factible en las dictaduras por la existencia de reglas o prácticas parlamentarias que posibilitan la presencia de diferentes temas en las votaciones. En las cámaras electas de la Restauración europea puede ser a través de la contestación al discurso de la Corona, el ejercicio del derecho de petición, el desarrollo de las funciones financieras o la presentación de proyectos de ley. Bajo estas condiciones, cualquier resultado es posible en las votaciones del Parlamento y la posibilidad de derrotar al status quo constituye uno de sus rasgos característicos (Mckelvey, 1976; Plott, 1967; Riker, 1980; Shepsle y Bonchek, 1997).

Por otra parte, la provisión de bienes públicos bajo la regla de la mayoría comporta conflictos distributivos en las Cámaras electas de las autocracias porque los parlamentarios, salvo que tengan preferencias idénticas, obtienen diferentes costes y beneficios de los resultados de las votaciones. Cualquier cuestión que se aprueba —el sistema electoral, la organización del ejército o los presupuestos - casi inevitablemente perjudica a una parte de los representantes. Debido a ello se produce un proceso de redistribución desde aquellos parlamentarios que resultan afectados por la decisión colectiva hacia aquellos que resultan beneficiados (Mueller, 2003).

¿Existe alguna alternativa a la inestabilidad predicha por los teoremas de la teoría espacial del voto? Sí, siempre que se incluya el factor institucional en el esquema teórico. Frente al mundo atomizado de la pura regla de la mayoría, cabe la posibilidad de una institución de equilibrio en la Cámara. Los parlamentarios pueden imaginar el arreglo institucional de la coalición duradera frente a opciones inestables como la votación independiente y sincera o una coalición formada en torno a una sola cuestión (Riker, 1980; Shepsle, 1986, 1989; Weingast, 1996).

Pero, ¿qué beneficios pueden obtener los parlamentarios con una coalición legislativa en la Cámara electa de una dictadura? Los beneficios vienen dados por las reglas y prácticas institucionales. Así, en la Restauración europea la Cámara Alta de naturaleza aristocrática y los poderes legislativos del monarca - facultad de sancionar, potestad legislativa y facultad de convocar, suspender y disolver el Parlamento- disminuyen las virtuales ganancias legislativas en comparación con las asambleas democráticas. Pero a pesar de estas restricciones institucionales, representa una oportunidad para los opositores. La Cámara electa se puede trocar en una tribuna para demandar transformaciones políticas, susceptible de combinarse con la protesta callejera, ya sean insurrecciones u otras formas de movilización. En esto consiste la utilidad de la coalición legislativa para parlamentarios disidentes: fortalece su posición en la Cámara electa. Y viceversa, si los parlamentarios son partidarios de las alternativas defendidas por el rey, se convierte en un medio para enfrentarse a sus oponentes en la Cámara electa. Evidentemente, también resulta factible que se generen coaliciones legislativas con fines más 
modestos. Tal es el caso de políticos dispuestos a coordinarse para promover reformas parciales en el régimen.

De este modo, las Cámaras electas de las dictaduras pasan de ser únicamente una herramienta en manos del régimen a transformarse - como Schedler (2013) ha planteado para las elecciones multipartidistas bajo el autoritarismo- en una arena de confrontación política. El autócrata se encuentra con parlamentarios disidentes que deciden articular una coalición legislativa para llevar a la cámara problemas y alternativas que ponen en cuestión su régimen y que son respaldadas por segmentos de la población, con derecho al voto o no. O parlamentarios reformistas que se coaligan para promover cambios parciales.

Por último, la coalición duradera implica el abandono del voto sincero y el ejercicio del voto sofisticado propio del comité. En la votación sincera, los representantes políticos votan las propias preferencias, al margen de las acciones que esperan de los otros parlamentarios. En cambio, en la votación estratégica votan para producir el resultado más deseado partiendo de un proceso de decisión. Esto es, el voto es una elección entre un conjunto de votos futuros. Este comportamiento resulta factible en las Cámaras electas de las dictaduras a pesar de las restricciones. Cuando se inicia una legislatura y se suceden las sesiones, la Cámara electa goza de estabilidad y carácter repetitivo y cabe la posibilidad de que se introduzcan diferentes temas para su deliberación y votación. Ello facilita a los representantes disponer de información para comprender el beneficio del voto sofisticado y conocerse lo suficiente unos a otros para saber quiénes tienen preferencias similares e interés en concertar su voto (Aldrich, 1995, 2011; Shepsle y Bonchek, 1997).

De la discusión anterior se pueden extraer estas tres hipótesis, que funcionan interactivamente y bajo la condición ceteris paribus:

- H1. La probabilidad de que se forme una coalición duradera aumenta cuando la Cámara electa de una dictadura se convierte en un espacio temático multidimensional.

- H2. La probabilidad de que se forme una coalición duradera aumenta cuando en la Cámara electa de una dictadura surgen conflictos distributivos.

- H3. La probabilidad de que se forme una coalición duradera aumenta cuando en la Cámara electa de una dictadura se puede practicar el voto sofisticado.

\section{METODOLOGÍA Y DATOS}

El origen del PP y el PM pone en cuestión el saber establecido sobre la formación de partidos en las dictaduras. No responden al modelo de partido de origen externo. Estos partidos no son promovidos ni por la reina regente María Cristina antes del inicio de la primera legislatura del Estamento de Procuradores en el verano de $1834 \mathrm{ni}$ por círculos políticos excluidos de esta Cámara. Por el contrario, tienen un origen interno, a partir de coaliciones legislativas de procuradores; un proceso que se puede 
explicar por medio del esquema teórico y las tres hipótesis desarrolladas en el apartado anterior.

El interés analítico de las coaliciones avanzada y moderada en el Estamento de Procuradores radica en tres de sus características. Primero, estas coaliciones legislativas se generan tras una década de absolutismo (1823-1833) y después de las primeras elecciones, en junio de 1834, carentes de los rasgos propios de un enfrentamiento partidista. Segundo, hasta las elecciones de julio de 1836 no hay coordinación de candidaturas ni asociaciones electorales. Tercero, esta división parlamentaria entre avanzados y moderados se inicia en la primera legislatura del Estamento de Procuradores. En definitiva, no hay continuidad con coaliciones legislativas o candidaturas preexistentes, que dificultaría separar los resultados que son consecuencia directa del comportamiento de los procuradores.

El análisis del espacio temático multidimensional, los conflictos distributivos, el voto estratégico y las coaliciones avanzada y moderada se realiza a partir de la minuciosa investigación realizada por estudiosos de la política de la época, las reglas y prácticas parlamentarias y las sesenta votaciones nominales registradas — treinta y seis en la primera legislatura, nueve en la segunda y quince en la tercera- en el Estamento de Procuradores, compuesto por 188 miembros. Sin esta intensiva investigación previa sobre qué ocurrió en el régimen del Estatuto Real no se podría responder a la pregunta planteada en este trabajo: por qué ocurrió.

El espacio temático multidimensional se ha reconstruido mediante el análisis de las cuestiones con votaciones nominales registradas en el Diario de Sesiones de Cortes del Estatuto Real. Estamento de Procuradores (legislaturas de 1834-1835, 1835-1836 y 1836). Los conflictos distributivos se observan en las deliberaciones y votaciones de estas cuestiones. La posibilidad de ejercicio del voto sofisticado se manifiesta en las reglas y prácticas parlamentarias, las relaciones entre los procuradores y las conexiones de procuradores con órganos de prensa como La Abeja o Eco del Comercio. Por último, la información para comprobar la articulación de las coaliciones avanzada y moderada procede de la actividad desarrollada por los procuradores más destacados dentro y fuera de las Cortes y los resultados —a favor, en contra, abstención o ausencia- de las votaciones nominales registradas.

\section{ANÁLISIS EMPÍRICO}

El Estatuto Real (19-4-1834) fue promulgado por la reina regente María Cristina en nombre de su hija Isabel II, menor de edad. Se limitó a regular la organización de las dos Cámaras de las Cortes, el Estamento de Próceres y el Estamento de Procuradores. Se centró en su estructura, composición, poderes del rey, atribuciones y funcionamiento. No contenía ningún título dedicado a la soberanía nacional, los derechos políticos o las relaciones entre el Gobierno y las Cortes. El Estamento de Próceres estaba compuesto de forma vitalicia y en número ilimitado por miembros natos, como arzobispos y obispos o grandes de Espańa, y otros designados por el monarca entre los 
títulos de Castilla, embajadores, miembros del generalato o servidores de la Administración. El Estamento de Procuradores era de naturaleza electiva. Para ser procurador se precisaba tener treinta ańos y una renta anual de 12000 reales, con una duración de tres años y la posibilidad de ser reelegible. El derecho de sufragio era muy restringido, ya que lo ejercían solamente los mayores contribuyentes de cada localidad (Villarroya, 1968).

El rey tenía dos facultades legislativas. El art. 31 le concedía la iniciativa legislativa con carácter exclusivo y el art. 33 le atribuía la sanción de las leyes. Asimismo, el monarca poseía tres atribuciones sobre el funcionamiento de las Cortes: primero, el art. 24 le concedía la potestad de convocarlas; segundo, el art. 37 le reservaba la facultad exclusiva de cerrarlas, y tercero, los arts. 24 y 40 le atribuían la capacidad de disolverlas. La función legislativa de las Cortes, dadas las competencias del monarca, se limitaba al derecho de petición y a la aprobación de las leyes por las dos Cámaras. En definitiva, el Estamento de Próceres y los poderes legislativos del rey — facultad de sancionar, potestad legislativa y capacidad de convocar, suspender y disolver el Parlamento- reducían el potencial legislativo del Estamento de Procuradores en comparación con el Congreso de los Estados Unidos o la Asamblea Nacional de la Francia revolucionaria (ibid.).

El régimen del Estatuto Real contaba con el respaldo de una parte del liberalismo, reflejado en el apoyo de un amplio grupo de procuradores, mayoritario en las dos primeras legislaturas, y los dos primeros Gobiernos - Martínez de la Rosa y Torenoy el último, presidido por Istúriz. Pero se encontró con la oposición de los carlistas, que derivó en su rechazo a la participación en las Cortes y el desarrollo de una guerra civil, y de un sector liberal que ambicionaba un cambio político que fuera más allá del Estatuto Real. Esta disidencia se manifestó en la actitud opositora de un nutrido número de procuradores, particularmente en la tercera legislatura, y en levantamientos, como la revuelta del verano de 1835 . Tras este acontecimiento, la reina regente María Cristina nombró a Juan Mendizábal como sucesor del conde de Toreno, que se mantuvo durante la segunda legislatura y parte de la tercera, cuando fue sustituido por Istúriz (Adame de Hue, 1997; Artola, 1974; Burdiel, 1987; Janke, 1974; Marichal, 1980; Tomás y Valiente, 1972).

\section{Espacio temático multidimensional}

Ninguna de las tres legislaturas del Estamento de Procuradores agotó los tres años de mandato parlamentario. La primera duró alrededor de diez meses — del 21 de julio de 1834 al 29 de mayo de 1835-; la segunda, sin elecciones por medio, un poco más de dos meses — del 16 de noviembre de 1835 al 27 de enero de 1836-, y la tercera, dos meses — del 22 de marzo de 1836 al 22 de mayo de 1836-. Sin embargo, en estos catorce meses se introdujeron y votaron numerosas cuestiones en la Cámara electa. Las sesenta votaciones nominales registradas reflejan esta actividad parlamentaria —anexos A y B- (Artola, 1974; Burdiel, 1987; Monerri, 2017). 
Con ello se confirma la primera hipótesis sobre las condiciones de posibilidad de las coaliciones legislativas. La probabilidad de que se forme una coalición duradera aumenta cuando la Cámara electa de una dictadura se convierte en un espacio temático multidimensional

Este resultado se explica por el efecto de siete reglas y prácticas parlamentarias: la contestación al discurso de la Corona; el ejercicio del derecho de petición; la deliberación sobre asuntos graves; la presentación de proyectos de ley; el voto de confianza; el examen de los presupuestos y subsidios, y el voto de censura:

- Primero, el Estamento de Procuradores discute y aprueba la contestación al discurso de la Corona. El proyecto de contestación debe ser objeto de debate público en sesión plenaria, como paso previo a su votación. Durante el debate y las votaciones subsiguientes queda patente el grado de apoyo que el Gabinete tiene en la Cámara.

- Segundo, mediante el derecho de petición el Estamento de Procuradores puede elevar una demanda a la Corona, para que ejercite su capacidad de proponer la oportuna ley. De este modo, la Cámara delibera desde el inicio de la primera legislatura sobre temas que los Gobiernos no querían que fuesen objeto de discusión pública.

- Tercero, la Corona puede convocar a los representantes para tratar asuntos graves, como es el caso durante la primera legislatura del examen y sanción del comportamiento del infante don Carlos.

- Cuarto, el Gobierno presenta los proyectos de ley en la Cámara. El procedimiento legislativo consiste en remitir el proyecto a una comisión y, una vez que presenta su dictamen, se inicia la discusión en el pleno de la Cámara.

— Quinto, el voto de confianza constituye una delegación legislativa solicitada por el Gobierno al Estamento de Procuradores.

- Sexto, el examen de los presupuestos, contribuciones o subsidios afecta a los diferentes ministerios y la política general del Gabinete. Por tanto, también muestra el grado de confianza de la Cámara en el Gabinete.

- Séptimo, para hacer efectivo el voto de censura se recurre al mecanismo reglamentario de la petición y el trámite irregular de la proposición. Se trata de un medio de control que no figura en los reglamentos y se utiliza para diferentes fines (Adame de Hue, 1997; Artola, 1974; Burdiel, 1987; Marcuello, 1986, Villarroya, 1968).

\section{Conflictos distributivos}

Una serie de cuestiones con votaciones nominales registradas suscita división en el Estamento de Procuradores. La literatura destaca en la primera legislatura la contestación al discurso de la Corona, la petición de derechos, el arreglo de la deuda pública extranjera, la aprobación de las actas de procuradores de Antonio Alcalá Galiano y 
Antonio Argüelles, el proyecto de ley de organización de la milicia urbana, la petición de aumento y movilización de la milicia urbana, el presupuesto y el voto de censura contra el Gabinete Martínez de la Rosa. En la segunda sobresale el proyecto de ley electoral. $Y$ en la tercera, el nuevo proyecto de ley electoral y el voto de censura contra el Gobierno Istúriz (Artola, 1974; Burdiel, 1987; Marichal, 1980; Monerri, 2017).

Estas votaciones divididas se deben a la presencia de conflictos distributivos, que se manifiestan en las deliberaciones y votaciones. Por lo que respecta a la primera legislatura, en la contestación al discurso de la Corona, la comisión encargada de elaborar la respuesta presentó un dictamen que constituye un desafío al Gobierno Martínez de la Rosa. Incluía demandas como la libertad de imprenta, la igualdad ante la ley, la seguridad personal o la independencia judicial. El Gabinete se manifestó en contra del proyecto de contestación y a favor de los principios de moderación del Estatuto Real. Como la redacción final de la contestación al discurso de la Corona no convenció a los procuradores disconformes con el Gabinete Martínez de la Rosa, presentaron la citada petición de derechos. En el arreglo de la deuda pública extranjera, la confrontación vino dada por el reconocimiento de la deuda contraída, particularmente durante la anterior etapa absolutista. Como ya se ha indicado, para ser procurador se requería poseer una renta anual de 12000 reales. La Comisión de Poderes del Estamento de Procuradores consideró que en relación con este punto la situación de Antonio Alcalá Galiano y Antonio Argüelles presentaba ciertas irregularidades.

La discusión sobre el proyecto de ley de la milicia urbana se centró en los artículos que regulaban la milicia como obligación y establecían los requisitos necesarios para tomar parte en ella. Los procuradores críticos con la propuesta presentada abogaron por la voluntariedad porque la obligatoriedad podría hacer que muchos desafectos al régimen formaran parte de ella. Y en caso de admitirse, debería especificarse la exclusión de los sospechosos de carlismo y los voluntarios realistas. En la petición sobre aumento y movilización de la milicia urbana, firmada por sesenta procuradores, se pedía a la reina que sancionara el proyecto de ley sobre milicia urbana aprobado por las Cortes, se insistía en que las autoridades provinciales debían tener órdenes precisas para impulsar el alistamiento y organización de los cuerpos y se reclamaba la formación de milicias urbanas móviles en las provincias. La discusión del presupuesto dio lugar a posiciones encontradas sobre el funcionamiento de la Administración y la política general del Gobierno. Por último, setenta procuradores (37,2\% de la Cámara) firmaron una proposición para pedirle al Estamento de Procuradores que aprobara una petición donde se juzgara inadecuada la acción del Gabinete Martínez de la Rosa (Artola, 1986; Burdiel, 1987; Fontana, 1973, 1977; Garzón, 1978; Monerri, 2017; Montañés, 2016).

En la segunda legislatura, el proyecto de ley sobre el sistema electoral generó tres conflictos distributivos en el Estamento de Procuradores. El primero estuvo motivado por el sistema de elección, con la confrontación de tres alternativas: un sistema indirecto, un sistema directo y un sistema mixto. El segundo vino dado por la determinación del cuerpo electoral en un contexto de voto censitario. Hubo dos posiciones: una defendía una cuota fija de contribuyentes; la otra, que votaran los mayores contribuyentes y se reconocieran determinadas capacidades. El tercero atañía al tamaño del 
distrito electoral. En la Cámara, parte de los procuradores defendieron el distrito uninominal y otros mostraron su preferencia por el distrito multinominal o provincial (Artola, 1974; Burdiel, 1987; Monerri, 2017).

En la tercera legislatura, el nuevo proyecto de ley electoral volvió sobre cuestiones que, como en la anterior legislatura, generaron conflictos distributivos. Se trata del sistema de mayores contribuyentes y reconocimiento del derecho de sufragio a las capacidades y el distrito multinominal. Por otra parte, el día 21 de mayo de 1836 se leyó una proposición firmada por 68 procuradores — 36,1\% de la Cámara- en la que se pedía al Estamento de Procuradores que «se sirv[iera] declarar que no obtienen su confianza los actuales Secretarios del Despacho", contrarios a las alternativas defendidas por el Gobierno sustituido. El voto de censura se aprobó por 78 votos a favor y 29 en contra. Al día siguiente, la reina regente María Cristina disolvió las Cortes (Artola, 1974; Burdiel, 1987; Monerri, 2017).

En resumen, los conflictos distributivos habidos en las tres legislaturas del Estamento de Procuradores responden a la segunda hipótesis sobre las condiciones de posibilidad para la estructuración de coaliciones legislativas en una Cámara electa. La probabilidad de que se forme una coalición duradera aumenta cuando en la Cámara electa de una dictadura surgen conflictos distributivos.

\section{Voto estratégico}

Las siete reglas y prácticas parlamentarias analizadas posibilitaron que los procuradores pudieran ejercer el voto sofisticado: les facilitaba el conocimiento de las preferencias de los demás miembros de la Cámara y su interés en alcanzar determinados compromisos. Por un lado, estas reglas y prácticas requerían deliberaciones y votaciones en comisiones o sesiones plenarias, sin olvidarse de los encuentros individuales y en grupo que se producían en dependencias de las Cortes, cafés o casas particulares o las colaboraciones e información en órganos de prensa como La Abeja, El Mensajero de las Cortes y Eco del Comercio. Por otro, la propia introducción de un tema para su deliberación y votación implicaba la concertación de un acuerdo entre parlamentarios. Por ejemplo, la presentación de una petición requería, al menos, la firma de doce procuradores - 6,3\% de la Cámara- y el informe favorable de dos de las tres comisiones que debían examinarla (Artola, 1974; Burdiel, 1987; Villarroya, 1968). En definitiva, los catorce meses de actividad del Estamento de Procuradores confirman la tercera hipótesis del esquema teórico: la probabilidad de que se forme una coalición duradera aumenta cuando en la Cámara electa de una dictadura se puede practicar el voto sofisticado.

\section{Coaliciones legislativas avanzada y moderada}

¿Qué relación hay entre el espacio temático multidimensional, los conflictos distributivos y la posibilidad de ejercer el voto sofisticado en el Estamento de Procuradores? 
Los temas y los conflictos distributivos se pueden ordenar a partir de una única dimensión política, resultado de la fractura ideológica construida por medio del acuerdo y ejercicio del voto sofisticado. Aunque los procuradores estaban en contra del carlismo y a favor del liberalismo, entre ellos surgieron discrepancias desde la primera legislatura sobre la actitud a adoptar ante el régimen del Estatuto Real. Esto es, si la Cámara electa debía seguir la pauta señalada por el Estatuto Real o, por el contrario, ir más allá. Como resultado, se estructuraron las coaliciones legislativas avanzada y moderada.

En los primeros comicios del Estatuto Real (junio de 1834) no hubo candidaturas y manifiestos electorales ni corrientes de opinión pública identificables con esta división ideológica. La discusión y votación del proyecto de contestación al discurso de la Corona en julio de 1834 supuso la primera manifestación pública de esta divergencia. Si el Estatuto Real era la expresión constitucional del liberalismo moderado, este documento, al demandar entre otros asuntos una serie de derechos políticos, condensaba parte de las aspiraciones del liberalismo avanzado. Pocos días después, la presentación de la petición solicitando la ampliación de derechos políticos reforzó las dos tendencias. En posteriores votaciones se observó de nuevo esta confrontación, que se mantuvo en la segunda legislatura, sobre todo con la ley electoral.

Este distanciamiento ideológico se confirmó en las segundas elecciones, celebradas en febrero de 1836. Aunque todavía no se formaron candidaturas ni se presentan manifiestos electorales, la pugna resultaba evidente. Se refleja en los editoriales y noticias de la prensa y también en los resultados electorales. La mayoría de los historiadores subrayan un dato: la casi total eliminación —atribuida a la acción gubernamental - de la oposición moderada, pues de los 71 procuradores que votaron en contra del distrito multinominal en la sesión del 24 de enero de 1836, el marqués de Someruelos fue el único que consiguió la reelección. En la tercera legislatura también se comprueba el enfrentamiento entre los avanzados y moderados — cuyas filas estaban encabezadas por exavanzados como Francisco Istúriz y Antonio Alcalá Galiano-, principalmente en el nuevo proyecto de ley electoral y el voto de censura contra el Gobierno Istúriz. En las elecciones de julio de 1836, la competencia electoral entre liberales avanzados y moderados fue abierta, con la presentación de candidaturas y asociaciones electorales respectivas (Agesta, 1977; Artola, 1974; Burdiel, 1987, Janke, 1974; Marichal, 1980; Monerri, 2017; Tomás y Valiente, 1972).

En definitiva, las coaliciones legislativas de avanzados y moderados en el Estamento de Procuradores derivaron en la rivalidad electoral y un incipiente desarrollo organizativo en los distritos. En un segundo momento, avanzados y moderados se embarcaron en la gestación de algo novedoso en la política española. Constituyeron los primeros partidos: el PP y el PM. Estos partidos de origen interno se convirtieron en canalizadores de la movilización política —incluido un repertorio de acciones armadas - y electoral y partidos gobernantes en las décadas centrales del siglo XIX (Agesta, 1977; Artola, 1974; Burdiel, 1987, Janke, 1974; Marichal, 1980).

Los investigadores de la confrontación entre avanzados y moderados en el Estamento de Procuradores no disponen de documentos como manifiestos o acuerdos firmados que muestren el conjunto de alternativas defendidas por unos y otros. Se ven 
obligados a recurrir a otras pruebas que revelen sus preferencias ideológicas. Siguen las acciones de los procuradores más activos en la Cámara -intervenciones, firma de peticiones, apoyo o rechazo a los diferentes Gobiernos o participación en la elaboración de proyectos de ley-, fuera de la Cámara — como las reuniones en casa de Fermín Caballero, procurador y director del Eco del Comercio- o las propuestas defendidas en El Mensajero de las Cortes y Eco del Comercio — de orientación avanzada - o La Abeja — de tendencia moderada-. En las dos primeras legislaturas entre los procuradores avanzados sobresalieron Joaquín María López, Fermín Caballero, Antonio Argüelles y el conde de las Navas; y entre los moderados, Francisco Martínez de la Rosa, Francisco Hubert y Muñoz y Diego Medrano. En la tercera legislatura destacaron de nuevo los avanzados José María López y Fermín Caballero, y los moderados y antiguos avanzados Francisco Istúriz y Antonio Alcalá Galiano (Artola, 1974; Burdiel, 1987; Monerri, 2017).

Por medio del análisis de estas pruebas documentales, los historiadores han logrado identificar las siguientes alternativas defendidas por unos y otros. Los procuradores avanzados en la primera legislatura se mostraron contrarios al Gobierno Martínez de la Rosa - durante el Gobierno Toreno las Cortes estuvieron cerradas-; a favor de la declaración de derechos; disconformes con el reconocimiento de la deuda pública contraída bajo el absolutismo; a favor de que se aprobaran las actas de procuradores de Antonio Alcalá Galiano y Antonio Argüelles; a favor de una milicia urbana formada por voluntarios y, en todo caso, a favor de la exclusión de los sospechosos; a favor de las medidas incluidas en la petición sobre la milicia urbana, y a favor del voto de censura contra el Gobierno Martínez de la Rosa. Los moderados defendieron la posición contraria en todas estas cuestiones. En la segunda legislatura, las diferencias se centraron sobre todo en dos asuntos de la ley electoral. Los avanzados defendieron el voto de los mayores contribuyentes y el reconocimiento de capacidades frente a la cuota fija de contribuyentes y el distrito multinominal, y los moderados fueron partidarios de las alternativas rivales. En la tercera legislatura, los procuradores avanzados y moderados mantuvieron las mismas diferencias de la segunda legislatura sobre la ley electoral, y los primeros promovieron el voto de censura y los segundos apoyaron al Gabinete Istúriz (Artola, 1974; Burdiel, 1987; Marichal, 1980; Monerri, 2017).

La división entre avanzados y moderados también se ve confirmada por las estrategias de votación seguidas por los procuradores moderados durante las dos últimas legislaturas en algunas cuestiones. En la segunda legislatura, a pesar de ser mayoría frente a los avanzados, tanto en la contestación al discurso de la Corona como en el voto de confianza apenas dejaron traslucir - por medio del voto a favor y la abstención-su rechazo al Gobierno Mendizábal. Los historiadores entienden que el levantamiento del verano de 1835 y el cambio de Gobierno explican este repliegue táctico de los moderados. En la tercera legislatura, los procuradores moderados decidieron en dos cuestiones -el cambio de Gobierno (de Mendizábal a Istúriz) y el restablecimiento de las leyes aprobadas durante el Trienio Liberal (1820-1823) sobre la extinción de mayorazgos, señoríos y diezmos - votar a favor y abstenerse, respectivamente, para evitar que el Gobierno Istúriz quedase en evidencia ante su escaso apoyo en el 
Estamento de Procuradores, efecto de los resultados electorales de febrero de 1836 (Burdiel, 1987).

En conclusión, el ejercicio del voto estratégico de procuradores avanzados y moderados explica la introducción de temas y la relación ideológica entre las alternativas con votaciones nominales registradas. Sin embargo, falta por cuantificar el alcance de esta polarización en la Cámara. Esto es, en qué medida las votaciones de los procuradores responden a esta estructura ideológica unidimensional. El cálculo se realiza por medio de WNOMINATE. Este paquete estadístico es el utilizado habitualmente en el análisis del comportamiento legislativo (Armstrong II et al., 2014; Poole y Roshental, 1997; Poole, 2005; Poole et al., 2011)3.

Cada parlamentario se representa en un espacio político abstracto por una posición en particular y cada voto nominal por dos posiciones: una para el sí y otra para el no. Los puntos ideales son estimados por medio del agrupamiento de los resultados de las votaciones nominales. La proximidad de los parlamentarios muestra el grado de similitud de sus registros de votación y la distribución de los parlamentarios indica cuáles son las dimensiones de conflicto principales. Pero como todo método de escalamiento, WNOMINATE no proporciona información sobre el contenido de estas dimensiones: hay que obtenerla de modo independiente. Por último, el paquete estadístico elimina las votaciones con una minoría inferior al 2,5\% y a los parlamentarios que no alcanzan un mínimo de veinte votos emitidos porque no sirven para la estimación de los puntos ideales.

Los datos sobre las votaciones nominales registradas proceden de la obra de Burdiel (1987). En ella figura información sistemática —a favor, en contra, abstención o ausencia - sobre el voto de los 188 procuradores de las tres legislaturas, con un total de 11280 observaciones. Sin embargo, solamente las 6768 observaciones de la primera legislatura sirven para la estimación de los puntos ideales de los procuradores. Esta legislatura supera las veinte votaciones nominales registradas con una minoría superior al $2,5 \%$ y hay parlamentarios que alcanzan el mínimo de veinte votos emitidos. En cambio, las otras dos legislaturas no alcanzan la cifra de veinte votaciones nominales registradas (nueve en la segunda legislatura y quince en la tercera). Por tanto, ninguno de los parlamentarios de las dos últimas legislaturas puede alcanzar el mínimo de veinte votos exigidos para la estimación de los puntos ideales. Esta falta de disponibilidad de datos limita el análisis cuantitativo. No obstante, con el cálculo de los puntos ideales de los procuradores de la primera legislatura se puede mensurar el conjunto de procuradores que inicia el proceso de formación del PP y el PM.

En el cuadro 1 se recogen los resultados del análisis estadístico de las votaciones nominales registradas en la primera legislatura del Estamento de Procuradores. WNOMINATE ha eliminado 125 procuradores $(66,48 \%)$ por la acumulación de ausencias y abstenciones: no llegan al mínimo de veinte votos exigidos para la estimación de sus puntos ideales. Es el caso de siete de los diez primeros procuradores analizados.

3. Disponible en: https:/CRAN.R-project.org/package=wnominate. 
Asimismo, ha suprimido nueve votaciones nominales registradas $(25 \%)$ porque la minoría es inferior al 2,5\%.

Los datos de los 63 procuradores y las veintisiete votaciones nominales registradas seleccionados muestran que hubo polarización en el Estamento de Procuradores y vino dada por la dimensión ideológica avanzados/moderados. Los valores de Correct Classification — 90,78\%—, APRE (Aggregate Proportional Reduction in Error) - 0.759- y GMP (Geometric Mean Probability) - 0.806- indican que hubo una estructura ideológica unidimensional en las votaciones de la primera legislatura del Estamento de Procuradores. Unos resultados que respaldan los hallazgos del estudio cuantitativo de Burdiel (1987), basado en el análisis factorial y el análisis de correspondencias. Aproximadamente la tercera parte de los procuradores de la primera legislatura participó en las coaliciones avanzada y moderada por medio del ejercicio del voto sofisticado. El resto de los parlamentarios, por diversas razones, no tuvieron este comportamiento estratégico. Estos 63 procuradores son «el núcleo y el origen de la división interna del liberalismo parlamentario de 1834-35" (ibid.: 135). Por tanto, el Estamento de Procuradores no está fracturado mayoritariamente entre avanzados y moderados, como argumenta Fermín Caballero en el momento y recoge la investigación histórica posteriormente. Solamente una parte de los parlamentarios se decanta por la implicación en una u otra coalición legislativa (ibid:: 153).

Cuadro 1.

Summary of W-NOMINATE OBJECT

Number of Legislators: $\quad 63$ (125 legislators deleted)

Number of Votes: 27 (9 votes deleted)

Number of Dimensions: 1

Predicted Yeas: 695 of $772(90 \%)$ predictions correct

Predicted Nays: 615 of $671(91.7 \%)$ predictions correct

Correct Classifiction: $90.78 \%$

APRE: $\quad 0.759$

GMP: $\quad 0.806$

The first 10 legislator estimates are: coord1D

Abargues $\quad-0.369$

Acevedo $\quad-0.079$

Acuña NA

Aguirre NA

Alcalá Galiano NA

Alcalá Zamora $\quad-1.000$

Alcántara NA

Almodóvar NA

Álvarez de Sotomayor NA

Álvarez García NA

Fuente: elaborado por Alejandro Domínguez. 
Este hecho suscita una pregunta: $;$ es suficiente un grupo de este tamaño para originar dos partidos? La información acumulada por los historiadores así lo señala. Primero, estos procuradores fueron los generadores de la polarización ideológica en el Estamento de Procuradores y mantuvieron «un auténtico liderazgo político respecto al resto de la Cámara» (ibid.: 154), que se prolongó en las dos legislaturas siguientes. No hubo ninguna otra confrontación ideológica reseñable en la Cámara. Segundo, esta división ideológica se proyectó más allá del Estamento de Procuradores. Avanzados y moderados la trasladaron a la competencia electoral en los comicios de julio de 1836, con la organización de candidaturas y asociaciones electorales en las circunscripciones. Tercero, estos dos grupos liberales fueron los promotores del PP y del PM.

Progresistas — como se conoce a las avanzados después del Estatuto Real- y moderados protagonizaron la movilización política —incluidas iniciativas armadasy electoral y sus partidos gobernaron en las décadas centrales del siglo xix, tal y como se observa en la siguiente selección de acontecimientos. Tras la rebelión de la guarnición de la Granja en agosto de 1836 la reina regente María Cristina llamó a gobernar a los progresistas en la persona de José María Calatrava. Estos liberales promovieron la Constitución de 1837. Los moderados ganaron las elecciones de septiembre del mismo año. La reina regente le encomendó al moderado Pérez de Castro la presidencia del Consejo de Ministros a finales de 1838, tarea que se prolongó hasta julio de 1840. La revolución del verano de ese año supuso una victoria para los progresistas. Espartero, máximo dirigente del PP entre 1840 y 1856, se ocupó de la Regencia entre 1841 y 1843 (Agesta, 1977; Artola, 1974; Burdiel, 1987, Janke, 1974; Marichal, 1980). En definitiva, la formación del PP y del PM no se inició fuera del marco parlamentario. Son partidos de origen interno, cuyos impulsores originarios fueron estos miembros de la primera legislatura del Estamento de Procuradores.

\section{CONCLUSIONES}

La investigación realizada sobre las coaliciones legislativas de liberales avanzados y moderados en el Estamento de Procuradores durante el régimen del Estatuto Real confirma las tres hipótesis sobre los incentivos e información para la formación de coaliciones duraderas. Primero, las votaciones nominales registradas muestran que se convierte en un espacio temático multidimensional por medio de siete reglas y prácticas parlamentarias: la contestación al discurso de la Corona; el ejercicio del derecho de petición; la deliberación sobre asuntos graves; la presentación de proyectos de ley; el voto de confianza; el examen de los presupuestos y subsidios, y el voto de censura. Segundo, en la Cámara surgen conflictos distributivos, ya sea por la petición de derechos, la milicia urbana o la ley electoral. Tercero, los procuradores pueden ejercer el voto sofisticado. El acceso a información para comprender el beneficio del voto estratégico y el conocimiento de las preferencias de los demás procuradores y su interés en concertar su voto se alcanza a través de las deliberaciones y las votaciones, los 
encuentros individuales y en grupo dentro y fuera de las Cortes, y las colaboraciones e información en órganos de prensa.

Mediante el análisis cualitativo se ha verificado la construcción de coaliciones en las tres legislaturas por medio del acuerdo y el voto estratégico. Las coaliciones avanzada y moderada defienden un conjunto de alternativas enfrentadas: a favor o en contra de la declaración de derechos; a favor o en contra del voto de censura contra el Gobierno Martínez de la Rosa, o a favor o en contra del distrito multinominal. Por medio del análisis cuantitativo se ha mensurado el tamaño de las coaliciones originarias: participa la tercera parte de los procuradores de la primera legislatura a través del voto sofisticado. No obstante, este análisis se ve limitado por la falta de disponibilidad de datos para las dos últimas legislaturas. Por último, se ha mostrado que los procuradores avanzados y moderados son los promotores de las primeras candidaturas y asociaciones electorales en las circunscripciones y los dos primeros partidos de España, el PP y el PM.

Este caso de estudio pone en cuestión el saber establecido sobre la formación de partidos en las dictaduras. Frente a una explicación excluyente del partido de origen interno, esta investigación muestra la plausibilidad de la hipótesis alternativa. De acuerdo con el esquema teórico de la coalición duradera, cabe la posibilidad de que en las Cámaras electas de las dictaduras se den los incentivos e información propiciatorios de estas coaliciones y los parlamentarios decidan cooperar, y que esta coordinación legislativa derive en la gestación de un partido. Por tanto, la explicación de la construcción de los partidos en los regímenes dictatoriales debe basarse, al igual que ocurre en las democracias, en dos tipos de partidos: de origen interno y origen externo.

La investigación empírica de los partidos de origen interno en las dictaduras no debería centrarse en el autoritarismo posterior a la II Guerra Mundial. Habría que buscar escenarios legislativos con parlamentarios sin previos compromisos de partido. En este sentido, el camino seguido por los estudiosos del origen de los partidos en las democracias debería servir de guía. Habría que investigar autocracias del pasado con Cámaras electas, como se ha hecho para las democracias con las primeras legislaturas del Congreso de los Estados Unidos. Se podría analizar sistemáticamente el comportamiento de los parlamentarios de las Cámaras electas de los regímenes despóticos de la Restauración europea. En Alemania, Francia, Italia, Polonia y Portugal puede haberse dado experiencias de coaliciones legislativas duraderas comparables a la espańola del Estatuto Real. No es descartable la posibilidad de que en el futuro vuelvan a darse las circunstancias favorables para la articulación de estas coaliciones legislativas en parlamentos de sistemas autoritarios.

\section{AGRADECIMIENTOS}

Agradezco a Alejandro Domínguez (Universidad de Vigo) su valiosa ayuda en el tratamiento estadístico de los datos con el programa WNOMINATE. Asimismo, agradezco los comentarios y sugerencias de Ignacio Lago y dos evaluadores anónimos 
de la Revista Española de Ciencia Política. Obviamente, la responsabilidad sobre el contenido del texto es enteramente mía.

\section{Referencias}

Adame de Heu, Wladimiro. 1997. Sobre los orígenes del liberalismo histórico consolidado en España (1835-1840). Sevilla: Universidad de Sevilla.

Agesta, Luis. 1977. «El origen de los partidos políticos en la España del siglo XIX», en José Luis Aranguren et al., Historia Social de España. Madrid: Guadiana.

Aldrich, John. 1995. Why Parties? The Origin and Transformation of Political Parties in America. Chicago: The University Chicago Press. Disponible en: https://doi. org/10.7208/chicago/9780226012773.001.0001.

Aldrich, John. 2011. Why Parties? A Second Look. Chicago: The University of Chicago Press.Disponibleen:https://doi.org/10.7208/chicago/9780226012759.001.0001.

Aprile, Sylvie, Jean-Claude Caron y Enmanuel Fureix. 2013. La liberté guidant les peuples. Les révolutions e 1830 en Europe. Seyssel: Camp Vallon.

Armstromg II, David, Ryan Bakker, Royce Carroll, Christopher Hare, Keith Poole y Howard Roshental. 2014. Analyzing Spatial Models of Choice and Judgment with $R$. Boca Raton, Londres, Nueva York: CRC Press.

Artola, Miguel. 1974. Partidos y programas politicos, 1808-1936. Madrid: Aguilar.

Artola, Miguel. 1986. La hacienda del siglo XIX: progresistas y moderados. Madrid: Alianza Editorial.

Arrow, Kenneth. 1963. Social Choice and Individual Values. New Haven, CT: Yale University Press.

Blanco, Roberto. 2010. La construcción de la libertad: apuntes para una historia del constitucionalismo europeo. Madrid: Alianza Editorial.

Boix, Carles, Michael K. Miller y Sebastian Rosato. 2013. «A complete data set of political regimes, 1800-2007», Comparative Political Studies, 46: 1523-1554. Disponible en: https://doi.org/10.1177/0010414012463905.

Burdiel, Isabel. 1987. La politica de los notables. Moderados y avanzados durante el Régimen del Estatuto Real (1834-1836). Valencia: Edicions Alfons El Magnànim.

Caron, Jean-Claude y Jean-Philippe Luis (dirs.). 2015. Rien appris, rien oublié? Les Restaurations dans L'Europe postnapoléonienne (1814-1830). Rennes: Presses Universitaires de Rennes. Disponible en: https://doi.org/10.4000/books.pur.95956.

Colomer, Josep. 2009. Manual de ciencia politica. Barcelona: Ariel.

Duverger, Maurice. 1987. Los partidos políticos. México DF: Fondo de Cultura Económica.

Fontana, Josep. 1973. Hacienda y Estado en la crisis del Antiguo Régimen español: 19231933. Madrid: Instituto de Estudios Fiscales.

Fontana, Josep. 1977. La revolución liberal. Política y Hacienda en 1833-1845. Madrid: Instituto de Estudios Fiscales. 
Gandhi, Jennifer. 2008. Political Institutions under Dictatorship. Nueva York: Cambridge University Press. Disponible en: https://doi.org/10.1017/CBO9780511510090.

Gandhi, Jennifer y Adam Pzeworski. 2007. "Authoritarian Institutions and the Survival of Autocrats", Comparative Political Studies, 40: 1279-1301. Disponible en: https://doi.org/10.1177/0010414007305817.

Garzón, Juan Sisinio P. 1978. Milicia nacional y revolución burguesa: el prototipo madrileño. 1808-1874. Madrid: CSIC.

Geddes, Barbara, 1999. "What Do We Know about Democratization after Twenty Years?», Annual Review of Political Science, 2: 115-44.

Disponible en: https://doi.org/10.1146/annurev.polisci.2.1.115.

Geddes, Barbara. 2005. "Why Parties and Elections in Authoritarian Regimes». Paper prepared for the Annual Meeting of the American Political Science Association, Washington DC.

Geddes, Barbara. 2008. "Party Creation as an Autocratic Survival Strategy». Unpublished manuscript, UCLA.

Geddes, Barbara, Joseph Wright y Erica Frantz. 2018. How Dictatorships Work. Power, Personalization, and Collapse. Cambridge: Cambridge University Press. Disponible en: https://doi.org/10.1017/9781316336182.

Gerring, John. 2007. Case Study Research: Principles and Practices. Cambridge: Cambridge University Press.

Hinich, Melvin y Michael Munger. 1997. Analytical Politics. Cambridge: Cambridge University Press. Disponible en: https://doi.org/10.1017/CBO9781139174725.

Huntington, Samuel. 1994. La tercera ola. La democratización a finales del siglo XX. Barcelona: Paidós.

Janke, Peter. 1974. Mendizábal y la instauración de la monarquía constitucional en España (1790-1853). Madrid: Siglo XxI.

Marcuello, Juan Ignacio. 1986. La práctica parlamentaria en el reinado de Isabel II. Madrid: Congreso de los Diputados.

Marichal, Carlos. 1980. La revolución liberal y los primeros partidos politicos en España: 1834-1844. Madrid: Cátedra.

Mckelvey, Richard. 1976. "Intransivities in Multidimensional Voting Models and some Implicatioms for Agenda Control», Journal of Economic Theory, 12: 472-482. Disponible en: https://doi.org/10.1016/0022-0531(76)90040-5.

Monerri, Beatriz. 2017. Las Cortes del Estatuto Real (1834-1836). Universidad Complutense, Madrid.

Montañes, Enrique. 2016. «Deuda pública y cambio político. Los acreedores y la crisis del Estatuto Real, 1834-1835», en Salvador Calatayud, Jesús Millán y María Cruz (eds.), El Estado desde la sociedad. Espacios de poder en la España del siglo XIX. Alicante: Universidad de Alicante.

Mueller, Dennis C. 2003. Public Choice III. Cambridge: Cambridge University Press. Disponible en: https://doi.org/10.1017/CBO9780511813771.

Plott, Charles. 1967. "A Notion of Equilibrium and Its Possibility under Majority Rules», American Economic Review, 57: 787-806. 
Poole, Keith. 2005. Spatial Models of Parliamentary Voting. Cambridge: Cambridge University Press. Disponible en: https://doi.org/10.1017/CBO9780511614644.

Poole, Keith y Howard Rosenthal. 1997. Congress. A Polical-Economic History of Roll Call Voting. Nueva York; Oxford: Oxford University Press.

Poole, Keith, Jeffrey Lewis, James Lo y Royce Carroll. 2011. «Scaling Roll Call Votes with nominate in R», Journal of Statistical Software, 42: 1-21. Disponible en: http://dx.doi.org/10.2139/ssrn.1276082.

Prutsch, Markus. 2013. Making Sense of Constitutional Monarchism in Post-Napoleonic France and Germany. Basingstoke (etc.): Palgrave Macmillan. Disponible en: https://doi.org/10.1057/9781137291653.

Riker, William. 1980 «Implications from Disequilibrium of Majority Rue for the Study of Institutions», American Political Science Review, 74: 432-446. Disponible en: https://doi.org/10.1057/9781137271327.

Rohlfing, Ingo. 2012. Case Studies and Causal Inference. An integrative Framework. Basingstoke (etc.): Palgrave Macmillan. Disponible en: https://doi. org/10.1057/9781137271327.

Rosanvallon, Pierre. 1994. La monarchie imposible. Les chartes de 1814 et de 1830. París: Éditions Fayard.

Schedler, Andreas. 2013. The Politics of Uncertainty: Sustaining and Subverting Electoral Authoritarianism. Oxford: Oxford University Press. Disponible en: https:// doi.org/10.1093/acprof:oso/9780199680320.001.0001.

Shepsle, Kenneth.1986. «Institutional Equilibrium and Equilibrium Institutions», en Herbert Weisberg (ed.), Political Science: The Science of Politics. Nueva York: Agathon.

Shepsle, Kenneth. 1989. «Studying Institutions: some Lessons from a Rational Choice Approach", Journal of Theoretical Politics, 1: 131-142. Disponible en: https://doi. org/10.1177/0951692889001002002.

Shepsle, Kenneth y Mark Bonchek. 1997. Analyzing Politics. Rationality, Behavior, and Institutions. Nueva York: Norton and Company.

Tomás y Valiente, Francisco. 1972. El marco político de la desamortización en España. Barcelona: Ariel.

Villarroya, Joaquín T. 1968. El sistema político el Estatuto Real (1834-1836). Madrid: Instituto de Estudios Políticos.

Weingast, Barry.1996. «Political Institutions: Rational Choice Perspectives», en Robert Goodin y Hans-Dieter Kilingemn (eds.), New Handbook of Political Science. Oxford: Oxford University Press.

Presentado para evaluación: 26 de junio de 2019.

Aceptado para publicación: 11 de mayo de 2020. 


\section{ANEXO}

A. Votaciones nominales registradas en el Estamento de Procuradores (1834-1836)

Primera Legislatura

\begin{tabular}{|c|c|c|}
\hline Número & Fecha & Descripción \\
\hline 1 & $4 / 8 / 34$ & Contestación al Discurso de la Corona \\
\hline 2 & $1 / 9 / 34$ & Petición de derechos políticos. Totalidad \\
\hline 3 & $2 / 9 / 34$ & Petición de derechos políticos. Art. $1 .^{\circ}$ \\
\hline 4 & $5 / 9 / 34$ & Petición de derechos políticos. Art. 2. ${ }^{\circ}$ \\
\hline 5 & $6 / 9 / 34$ & Petición de derechos políticos. Art. 3. ${ }^{\circ}$ \\
\hline 6 & $8 / 9 / 34$ & Petición de derechos políticos. Art. $6 .^{\circ}$, primera parte \\
\hline 7 & $8 / 9 / 34$ & Petición de derechos políticos. Art. $6 .^{\circ}$, segunda parte \\
\hline 8 & $9 / 9 / 34$ & Petición de derechos políticos. Art. $7 .^{\circ}$ \\
\hline 9 & $10 / 9 / 34$ & Petición de derechos políticos. Art. $12 .^{\circ}$ \\
\hline 10 & $23 / 9 / 34$ & Arreglo Deuda Pública Extranjera. Totalidad \\
\hline 11 & $25 / 9 / 34$ & Arreglo Deuda Pública Extranjera. Art. 1. ${ }^{\circ}$ \\
\hline 12 & $26 / 9 / 34$ & Arreglo Deuda Pública Extranjera. Adición Sr. Morales al Art. 1. ${ }^{\circ}$ \\
\hline 13 & $27 / 9 / 34$ & Arreglo Deuda Pública Extranjera. Art. 3. ${ }^{\circ}$ \\
\hline 14 & $30 / 9 / 34$ & Arreglo Deuda Pública Extranjera. Art. $3 .^{\circ}$ reformado \\
\hline 15 & $7 / 10 / 34$ & Aprobación Acta Alcalá Galiano. Dictamen de la Comisión \\
\hline 16 & $8 / 10 / 34$ & Exclusión de D. Carlos. Totalidad \\
\hline 17 & $8 / 10 / 34$ & Exclusión de D. Carlos. Art. $1 .^{\circ}$ \\
\hline 18 & $15 / 10 / 34$ & Aprobación Actas Argüelles. Dictamen de la Comisión \\
\hline 19 & $11 / 11 / 34$ & Proyecto Organización Milicia Urbana. Totalidad \\
\hline 20 & $11 / 11 / 34$ & Proyecto Organización Milicia Urbana. Art. $1 .^{\circ}$, primera parte \\
\hline 21 & $11 / 11 / 34$ & Proyecto Organización Milicia Urbana. Art. $1 .^{\circ}$, segunda parte \\
\hline 22 & $13 / 11 / 34$ & Proyecto Organización Milicia Urbana. Art. 2. ${ }^{\circ}$ \\
\hline 23 & $18 / 11 / 34$ & Proyecto Organización Milicia Urbana. Adición al Art. 5. ${ }^{\circ}$ \\
\hline 24 & $20 / 12 / 34$ & Autorización plantear como Supletorios Presupuestos 1835.Totalidad \\
\hline 25 & $10 / 3 / 35$ & Petición Aumento y Movilización Milicia Urbana. Totalidad \\
\hline 26 & $12 / 3 / 35$ & Presupuesto Interior. Rentas Provinciales. Totalidad \\
\hline 27 & $1 / 4 / 35$ & Presupuesto Interior. Clases Pasivas. Dictamen Comisión Art. 6. \\
\hline 28 & $11 / 4 / 35$ & Presupuesto Interior. Deuda Pública Interior. Totalidad \\
\hline 29 & $24 / 4 / 35$ & Presupuesto Interior. Deuda Pública Interior. Art. $25 .^{\circ}$ \\
\hline 30 & $28 / 4 / 35$ & Presupuesto Interior. Deuda Pública Interior. Art. 26. Comisión \\
\hline 31 & $7 / 5735$ & $\begin{array}{l}\text { Presupuesto Interior. Deuda Pública Interior. Art. } 37 .^{\circ} \text { del Gobierno y } \\
400^{\circ} \text { de Comisión }\end{array}$ \\
\hline 32 & $5 / 5 / 35$ & $\begin{array}{l}\text { Proyecto organización y atribuciones de Ayuntamientos y Diputaciones. } \\
\text { Total }\end{array}$ \\
\hline 33 & $11 / 5 / 35$ & $\begin{array}{l}\text { Proposición control parlamentario del Gobierno. Totalidad (voto de } \\
\text { censura) }\end{array}$ \\
\hline 34 & $23 / 5 / 35$ & Petición. Extinción derechos Real Patrimonio. Totalidad \\
\hline 35 & $25 / 11 / 34$ & Quinta de 25.000 hombres. Totalidad \\
\hline 36 & $25 / 11 / 34$ & Quinta de 25.000 hombres. Art. 3. ${ }^{\circ}$ \\
\hline
\end{tabular}

Fuente: Burdiel (1987: 359-360). 
Segunda Legislatura

\begin{tabular}{ccl}
\hline Número & Fecha & Descripción \\
\hline 1 & $30 / 11 / 35$ & Contestación al Discurso de la Corona. Párrafo 2. ${ }^{\circ}$ \\
2 & $31 / 12 / 35$ & Voto de Confianza. Totalidad \\
3 & $3 / 6 / 36$ & Voto de Confianza. Art. 3. $^{\circ}$ \\
4 & $4 / 6 / 36$ & Ley Adicional de Organización de la Milicia. Totalidad \\
5 & $12 / 1 / 36$ & Ley Electoral (Mayoría Comisión). Totalidad \\
6 & $14 / 1 / 36$ & Ley Electoral. Art. 4. \\
7 & $17 / 1 / 36$ & Ley Electoral (Mayoría Junta). Art. 5. ${ }^{\circ}\left(2 .^{\circ}\right.$ parte) \\
8 & $20 / 1 / 36$ & Ley Electoral (Mayoría Junta). Art. 6. \\
9 & $24 / 1 / 36$ & Ley Electoral. Art. 17. \\
\hline
\end{tabular}

Fuente: Burdiel (1987: 375).

Tercera Legislatura

\begin{tabular}{|c|c|c|}
\hline Número & Fecha & Descripción \\
\hline 1 & $12 / 4 / 36$ & Contestación al Discurso de la Corona. Párrafo $11 .^{\circ}$ \\
\hline 2 & $13 / 4 / 36$ & Contestación al Discurso de la Corona. Párrafo $12 .^{\circ}$ \\
\hline 3 & $14 / 4 / 36$ & Contestación al Discurso de la Corona. Párrafo $18 .^{\circ}$ \\
\hline 4 & $25 / 4 / 36$ & Petición aprobación Decreto Extinción de Regulares \\
\hline 5 & $9 / 5 / 36$ & Ley Electoral. Totalidad \\
\hline 6 & $10 / 5 / 36$ & Ley Electoral. Art. 4.o \\
\hline 7 & $11 / 5 / 36$ & Ley Electoral. Art. $7 .^{\circ}$, párrafo $6 .^{\circ}$ \\
\hline 8 & $13 / 5 / 36$ & Ley Electoral. Art. $12 .^{\circ}$ \\
\hline 9 & $14 / 5 / 36$ & Ley Electoral. Art. $44 .^{\circ}, 1 .^{\circ}$ parte \\
\hline 10 & $14 / 5 / 36$ & Ley Electoral. Art. $44,4 .^{\circ}$ parte \\
\hline 11 & $15 / 5 / 36$ & Ley Electoral. Art. $44,4 .^{\circ}$ parte (voto particular) \\
\hline 12 & $15 / 5 / 36$ & Ley Electoral. Art. $44,4 .^{\circ}$ parte (nueva redacción) \\
\hline 13 & $16 / 5 / 36$ & Protesta cambio ministerial. Totalidad \\
\hline 14 & $19 / 5 / 36$ & Extinción mayorazgos, señoríos y diezmos. Totalidad \\
\hline 15 & $21 / 5 / 36$ & Voto de censura. Totalidad \\
\hline
\end{tabular}

Fuente: Burdiel (1987: 385).

B. Derecho de petición y espacio temático multidimensional en la primera legislatura del Estamento de Procuradores

Durante la primera legislatura el derecho de petición se convierte en uno de los cursos de acción seguidos por los procuradores disidentes para plantear en el Estamento de Procuradores cuestiones y alternativas no deseadas por la reina regente María Cristina y el liberalismo moderado. Esta estrategia contribuye a que la Cámara electa se convierta en un espacio temático multidimensional. Así lo demuestra el análisis de las 53 o 56 - los investigadores discrepan sobre el número total- peticiones presentadas (Artola, 1974; Burdiel, 1987; Monerri, 2015). 
Las peticiones formuladas en esta legislatura constituyen un programa de reformas en la organización social y política, al que se añaden reivindicaciones particulares de grupos a quienes su filiación liberal ha causado perjuicios en el pasado - la tercera petición pide la revalidación de los empleos conferidos en el Trienio Constitucional (1820-1823); la decimosexta, la de las ventas de bienes nacionales, y la trigésimo novena, la habilitación de los secularizados en aquellos años para obtener beneficios eclesiásticos-. Los cambios sociales que se reclaman persiguen la destrucción de la sociedad estamental. Se pide la desaparición de los tributos pagados a eclesiásticos y nobles — voto de Santiago (cuarta); merced de amigos (séptima); asaduras, castillaje y otros tributos (vigésimo segunda) — y la de las instituciones sobre las que se sustenta su influencia social. Así, la petición decimoséptima reclama la desamortización civil y eclesiástica; la decimonovena, la extinción de los mayorazgos y vinculaciones que no produzcan 33000 reales de renta líquida anual, y la decimoctava, la redención de los censos a favor de manos muertas en papel de rédito contra el Estado. Asimismo, los cambios políticos reclamados se orientan también hacia fines específicos, como la adquisición por las Cortes de la facultad de elaborar sus propios reglamentos (quinta); una nueva ley municipal con anterioridad a la nueva elección de diputados (decimotercera), o la constitución de una milicia urbana (decimocuarta y cuadragésimo cuarta).

\section{PEDRO LAGO}

plpenas@edu.xunta.gal

Doctor en Ciencia Política por la Universidad de Santiago de Compostela. Sus principales áreas de investigación son la acción colectiva y los partidos y movimientos sociales. Sus artículos han aparecido en Historia y Politica, Revista de Estudios Politicos o Revista Internacional de Sociología. Su último libro, titulado La construcción del movimiento sindical en sistemas politicos autoritarios. Las Comisiones Obreras de Galicia (1966-1975), ha sido publicado por La Catarata. En la actualidad está desarrollando un proyecto de investigación sobre la formación de coaliciones electorales en las elecciones durante la Segunda República española. 